\title{
THE EFFECTIVENESS OF SIMPLIFIED INTERVENTION PROGRAM FOR PREVENTING AND REDUCING LOW BACK PAIN AMONG MALAYSIAN BUS DRIVERS
}

\author{
${ }^{1}$ Shamsul Bahri Mohd Tamrin, ${ }^{2}$ Kazuhito Yokoyama, ${ }^{3} \mathrm{Li}$ Naing and ${ }^{1} \mathrm{Ng}$ Yee Guan \\ ${ }^{1}$ Department of Environmental and Occupational Health, \\ Faculty of Medicine and Health Sciences,Universiti Putra Malaysia, Malaysia \\ ${ }^{2}$ Department of Epidemiology and Environmental Health, \\ Faculty of Medicine, Juntendo University, Tokyo, Japan \\ ${ }^{3}$ Universiti Brunei Darussalam, Brunei Darussalam
}

Recived 2014-01-08; Recived 2014-01-30; Accepted 2014-03-01

\begin{abstract}
An intervention study was conducted in order to determine the effectiveness of an exercise program for reducing Low Back Pain (LBP) among bus drivers. A total of 197 bus drivers were randomly selected from a baseline study involving 1,197 drivers. Repeated Intervention programs (IN1 and IN2) were introduced which consist of a video programs, poster, pamphlet and demonstration. Pre-Intervention (pre-IN1 and preIN2) and post Intervention (post-IN1 and post-IN2) assessment studies the effect of the intervention programs to LBP and knowledge of respondents observed every 3 months. Knowledge score during Pre-IN 1 shows no significant difference between both groups whereas significant increase of knowledge was observed in Post-IN1, Pre-IN2 and Post-IN2 among the intervention group. The study revealed no significant changes of LBP complaints after post-IN1 in both group but a significant reduction of LBP among intervention group compared to the control group in the post-IN2. The effectiveness of the program was only seen after 6 months of the program.
\end{abstract}

Keywords: LBP, Exercise Program, Intervention, Bus Drivers

\section{INTRODUCTION}

Public transport is a vital means of transportation in urban and rural areas in Malaysia. In the year 2012 alone, the total number of bus rose to 73,536 from 69,149 , an increase of $6.3 \%$ of new buses across Malaysia (MOT, 2012). This increase was a result of the new initiatives under the Malaysia government's National Key Result Areas (NKRA) of the Economic Transformation Program which highlights the new initiatives for improvement of bus services. In addition, the total number of licenses for operating commercial bus increased from 297 licenses in the first quarter of 2012 to 472 licenses released by the Commercial Vehicle Licensing Board of Malaysia (MOT, 2012). It had been estimated that 35,000 passengers in Klang Valley alone currently travel by bus daily during the peak hour and with the initiative introduced, the capacity will be increased up to 55,000 users daily.

With the increase of bus drivers corresponding to the increase of licensed commercial bus operators, the driving condition and the safety and health of the bus drivers are not a major issue highlighted and has been overlooked by the Malaysian government's ETP. The statistics of accident shows that in the year 2010 alone, 9,580 accidents which involved buses occurred (contributing $1.2 \%$ of total accidents based on different type of vehicles) (MOT, 2010). Although the percentage is considerably low, the impact is considered as high risk as any single crash or disaster will results in loss or injuries to numerous lives as a high number of users are affected. Although no study has indicated direct

Corresponding Author: Shamsul Bahri Mohd Tamrin, Department of Environmental and Occupational Health,

Faculty of Medicine and Health Sciences, Universiti Putra Malaysia, Malaysia 
association between the prevalence of accident with the health status of the bus drivers, the issue should not be taken lightly. Our past survey (Tamrin, 2008) had shown that one of the important health issues among Malaysian bus drivers is the complaint of Musculoskeletal Disorders (MSD), beside hypertension and Type II diabetes.

Musculoskeletal Disorders (MSDs) are injuries and disorders of the muscles, nerves, tendons, ligaments, joints, cartilage and spinal disks. It has been reported by Occupational Safety and Health Administration USA (OSHA) that MSD injuries cost businesses from \$15 to $\$ 20$ billion in the form of compensation each year (OSHA, 1999). Occupations which are at high risk of developing MSD ranges from office workers to driving activities. Driving is related to high prevalence of MSD and has also been related with high prevalence of Low Back Pain (LBP) as reported by various authors (Anderson, 1992; Bovenzi and Hulshof, 1999; Guo et al., 2004; Johanning, 1991; Magnusson et al., 1996; Pope et al., 2002; Tamrin et al., 2007).

Study by Tamrin et al. (2012) among 1,181 bus drivers has shown that of all body parts, complaints of LBP $(58.5 \%)$ were the highest as compared to other body parts such as neck pain $(51.7 \%)$, upper back pain $(39.0 \%)$, followed by shoulder pain $(36.1 \%)$, leg pain $(28.9 \%)$, knee pain $(27.5 \%)$, hip and thigh pain $(19.9 \%)$, arm pain $(17.5 \%)$ and the lowest was elbow pain $(10.2 \%)$ respectively. Most of the epidemiological studies concluded that the occurrence of LBP and MSD is greater among bus drivers, compared to general population that are not exposed to specific risk factors such as whole body vibration and awkward postures. In addition, the readily installed bus drivers' seat that were not developed ergonomically may further increase the risk of developing LBP. There was also evidence that profile of psychological state plays a role in enhancing LBP complaints (Tamrin et al., 2007).

Considerable literatures have shown effectiveness and positive outcome from the intervention programs in reducing MSD and LBP among workers. Businesses that implement ergonomics intervention programs reported significant decrease in accidents, injuries and health care cost over time along with increase in productivity, quality of works and workers morale (Koda and Ohara, 1999).

Participatory intervention program have shown that if ergonomics principles are applied, the possibility of reducing LBP symptoms is achievable. Numerous intervention programs including education on LBP (Poosanthanasarn et al., 2005; Roland and Dixon, 1989), exercise programs (Brisson et al., 1999; Cambron et al., 2006; Lewis et al., 2001), "back school program"
(Forsell, 1980; 1981), ergonomics participation (Evanoff et al., 1999; Koda and Ohara, 1999; Moore and Garg, 1998; Poosanthanasarn et al., 2005; Robertson et al., 2002; Rosecrance and Cook, 2000), organizational and administrative intervention (Wahlstedt et al., 2000), intervention based on combination of epidemiological results and quantitatives methodologies (Poulsen et al., 2007) and engineering on ergonomics intervention (Aaras, 1994; Fredriksson et al., 2001; Johansson et al., 1993) were developed, implemented and evaluated, suggested that intervention programs are effective (with various degrees) in lowering the numbers of LBP or MSD sufferers. However, there is little evidence concerning the effectiveness of intervention programs developed being implemented on commercial bus drivers. A study by Johanning et al. (1996), (as the authors found currently) was the only study relating intervention program in reducing back disorders among commercial driver. However, the study focused was among mass transit operators which has a different nature of work compared to bus drivers and the intervention was done for a period of one year compared to our intervention program of 6 months duration. Mass transit operators performed driving on single track without the need to control traffic and driving electrical trains which has different risk compared to bus driving. The study found that $55.4 \%$ of LBP sufferers reported an improvement after the implementation of intervention program as compared to $12.3 \%$ experienced worsening pain conditions.

Although numerous reports associating driving with high prevalence of MSD, no suitable intervention program has been developed for drivers and especially, for commercial drivers. Therefore, intervention programs for managing and reducing LBP among bus drivers should consider the risk factors contributing to MSD. Most of the intervention programs relating to exercise were developed as a package of time consuming exercise program, expensive and difficult to sustain in a long period of time and found not suitable for commercial drivers due to their nature of work. Therefore, it is thought that an effective intervention program should focus on perseverance of the patient by developing an exercise program that is simple to practice by the drivers in many places either in their working place, or while taking a break from driving or even at home. As such, findings from this study can be applied not only to localize Malaysian bus drivers, but suitable for other land transportation globally especially in developing countries as engineering intervention are usually costly and time consuming to develop and test. In addition, as reported by previous study, the risk factors contributing 
to low back pain among bus drivers in most of the countries are identical.

The purpose of this study is to determine the knowledge about and the effectiveness of short term intervention program developed to reduce the complaints of LBP among Malaysian or bus drivers from other countries that have the similar traffic or MSD risks. The principle is to promote knowledge and practical training using the theory of change. It is expected that health promotion using a package of simplified training program would influence the driver's knowledge, motivate changes in driving behavior such as working posture, continuous exercise and treatment of LBP.

It is expected or as intended that the training and practice would improve the posture of the drivers. The continuous exercise will be able to reduce musculoskeletal loads and muscle fatigue and thus decrease LBP among them. Finally this will improvement the driver's health and in turn increase functional health, satisfaction and work productivity (Amick et al., 2003).

Funded under Intensified Research Priority Areas (IRPA) grant by The Ministry of Science, Technology and Innovation of Malaysia (MOSTI), the Commercial Vehicle Drivers Risk Management (COVERED) is a sub-project established under National Occupational Risk Management (NORM) project with its main objective to enhance the health of Malaysian bus drivers and to formulate preventive measures in increasing their safety, health and overall well-being.

\section{MATERIALS AND METHODS}

\subsection{Study Background and Design}

Before the study was executed, the research team together with the Malaysian commercial vehicle licensing board presented the study background to all the bus companies in all the regions. After the company had agreed to participate in the research, another detailed presentation was conducted at each of the company's office and the terms and conditions of the study was briefed. In addition to the main objective of the study, general health screening and souvenirs were distributed to 1,173 respondents' as a token of appreciation.

The study was divided into two phases. The first phase was to determine the prevalence of LBP among Malaysian bus drivers utilizing a cross sectional study design. A total of 1,173 male commercial bus drivers participated in the study. Nine States in Peninsular Malaysia were randomly selected to represent the Central, Eastern, Northern and Southern regions. Central region comprised of three states (federal territory, selangor and Negeri sembilan) participated by eight bus companies ( $\mathrm{n}=681$ drivers). The Eastern region, comprising the states of Kelantan and Pahang had 101 bus drivers from 2 bus companies. Two hundred and thirty six bus drivers participated from the Northern region (Penang, Kedah and Perak) and 152 bus drivers participated from the Southern region (Johor). In the first phase, the result of the study revealed a prevalence of $60.4 \%$ of LBP among commercial bus drivers (Tamrin et al., 2007) and the overall MSD of $81.8 \%$ (Tamrin et al., 2012).

Based on the findings in the first phase, the second phase involved respondents who had reported of having LBP for the past 12 months in the baseline study (total of 703 respondents that reported of having low back pain), where 197 respondents (representing 28\% of those reported having low back pain for the past 12 month) were randomly selected as experimental $(47.7 \%)$ and control (52.3\%) group. The intervention programs (second phase) were executed in a time frame of 9 months using true randomized experimental design with both groups comprising drivers with LBP during baseline and those without any complaint of LBP during baseline. The randomization was done using Epi Info ${ }^{\mathrm{TM}}$ ver 6.0. Figure 1 shows the overall flow of the study.

Out of 197 respondents, 35 participants $(83.2 \%$ retention rate) voluntarily withdrew from the study due to various reasons. Among the experimental group, 5 respondents quit during the 3 month follow up (5\% dropping rate), while 13 respondents quit the control group during the same period (13.6\% dropping rate). During the 6 month follow up, additional 10 respondents did not attend the program resulting in an additional $11.2 \%$ dropping rate whereas control group had an additional of 13 respondents who did not attend (14.6\% dropping rate).

In order to reduce the effect of the confounding factors, both groups were equally matched to ensure there were no significant difference in terms of LBP complaints $(\chi=0.809, \mathrm{p}=0.369)$, age $(\mathrm{t}=0.097, \mathrm{p}=$ $0.923)$, income level $(\mathrm{t}=-0.508, \mathrm{p}=0.612)$, education level $(\chi=5.480, \mathrm{p}=0.360)$ and part time job (Fischer exact $=0.619)$. Nevertheless, due to financial and time limitation, only three regions were selected, northern $(21.3 \%)$, central $(63.5 \%)$ and southern $(15.2 \%)$. The intervention program was conducted twice (IN1 and IN2) along with two assessment programs (AS1 and AS2). The programs were carried out in the intervals of 6 month with assessment programs done on the third month after each intervention program.

\subsection{Questionnaires}

Three sets of questionnaires were used in this study. The first was used to reveal socio-economic information, working conditions and baseline complaint of LBP. 


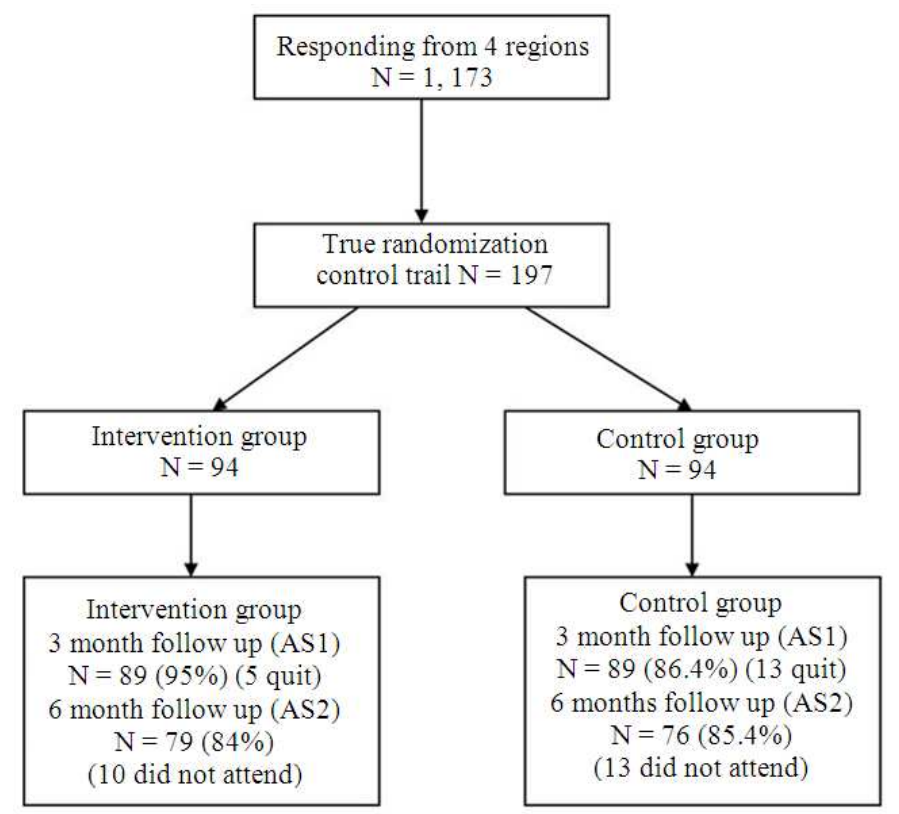

Fig. 1. Intervention program study flow

The second set of questionnaire was used to determine the level of knowledge regarding LBP (pre-IN and postIN, consisting of (1) principle knowledge of low back safety (2) correct driving postures (3) practices regarding exercise (4) pain management of back pain). The third questionnaire was used to assess the outcome of LBP three months after IN1 and 6 months after IN2.

To obtain information concerning the prevalence of LBP, a standardized and translated Malay language version of the english nordic questionnaire was used (Kuorinka et al., 1987). The Kappa measurement value (test-retest reliability) showed mild to moderate agreement (0.4-0.8) for the study variables.

Before each respondent was interviewed, they were briefed concerning the objective of the study and a signed written consent was obtained. At the end of the session, each booklet was checked to verify that all questions were answered.

\subsection{Development of Intervention Program}

The intervention program was developed using the information collected during the $1^{\text {st }}$ phase and also based on literatures. In developing the content, risk factors of LBP and MSD were based on the findings from binary logistic regression analysis adjusted for age, education level, work activities and income. The risk factors included in the content of the intervention program includes (a) lack of seat adjustability (b) seating comfort (c) exposure to whole body vibration (d) smoking (e) frequency of daily trips (f) duration of daily driving $(\mathrm{g})$ prolonged sitting $(\mathrm{g})$ working part time and (h) psychological factors.

The overall curriculum developed include: (1) statistics of accidents and prevalence of MSD, (2) risk factors of LBP, (3) adaptation of optimal ergonomics seating posture, (4) non-invasive treatment of LBP (the use of hot/cold pack), (5) exercise and stretching (in the morning, before driving, when seating in the bus and during rest) with each exercise requiring 10 to 16 repetitions and (6) correct lifting techniques. Using the above guidelines, the researchers developed a detailed storyboard that includes film, graphic/animation, screen title and narration. Before the final production of the video program, the storyboard was assessed and edited by a health promotion expert and occupational physician. The pamphlet, demonstration and video presentation were based on the storyboard so that the contents remained the same for all packages. The poster and pamphlet are additional tools to serve as reminders on the steps in proposed exercise and the type of risk. In order for them to easily use the poster and pamphlet, we requested that they stick it at conspicuous locations such as in their house and their resting area for them as reminder. In addition, a demonstrator was recruited by the authors to guide the participants for the first time on the correct method of exercise as shown in the video. The intervention program and materials used were 
presented in the native language of Malay as all of them are fluent in the language. The sample intervention program is shown in Fig. 2.

\subsection{Intervention Program}

IN1 and IN2 were introduced in sequence with video presentation introduced first followed by demonstration and practice by the participant. After that, they were given a package of video $\mathrm{CD}$, poster and pamphlet to be used at home or in their workplace. At the end of each intervention program, participants were reminded to continue practicing the exercise and prevention program given. As opposed to the intervention group, the control group was not exposed to any intervention program except a pack of sweetener as a placebo. The overall intervention program is summarized in Fig. 3 while Fig. 4 shows the implementation of intervention program.

Before IN1 and IN2 were demonstrated, a set of preintervention knowledge questionnaire (Cronbach's $\alpha=$ 0.856) (pre IN1 and IN2) regarding LBP was distributed to both groups. A post-intervention knowledge questionnaire (post IN1 and IN2) was distributed again after each intervention (IN1 and IN2) had finished. Knowledge between control and intervention group was compared for

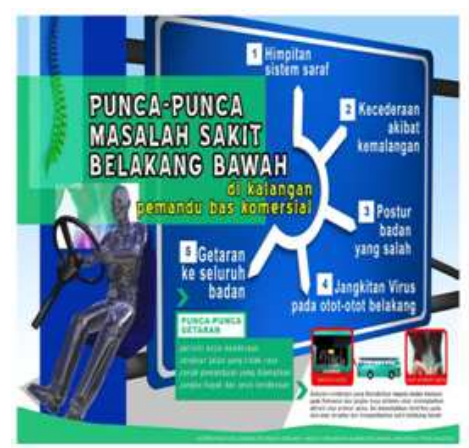

(A)

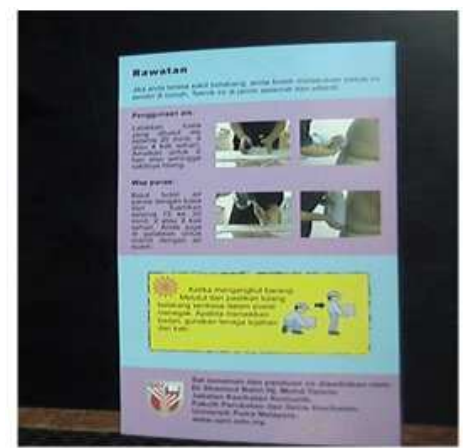

(C) pre IN1 and post IN2 as well as between pre-IN2 and postIN2. The questions test the knowledge of managing LBP such as "Do you know how to exercise while seating in a bus?" ( $0=$ No and $1=$ Yes $)$ with open ended question "If yes, describe the correct posture while seating in the bus......". Each correct answer was given a score of 1 . Another questionnaire (AS1 and AS2) consists of questions related to the complaint of LBP (within 7 days of the both AS1 and AS2) during the interval of 3 month after IN1 and after 6 month of IN2 An example of the questions asked was "For the past 7 days, do you have any back pain problems within 3 months after intervention program? $(0=$ No and Yes = 1) and for the control group, "For the past 7 days, do you have any back pain problems within 3 months? $(0=$ No and Yes $=1)$.

\subsection{Validity}

The internal validity of maturity was controlled by randomly selecting the participants of the same age group. The effect of testing or "test wise" was eliminated by performing a sequence of IN1 and IN2 of 6 month duration. The instrumentation factor was maintained by having the same instructor and demonstrators for the whole intervention and assessment programs.

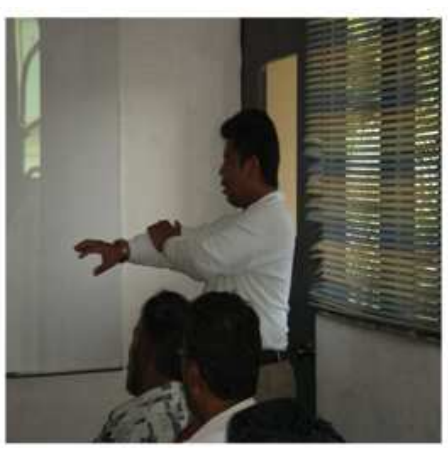

(B)

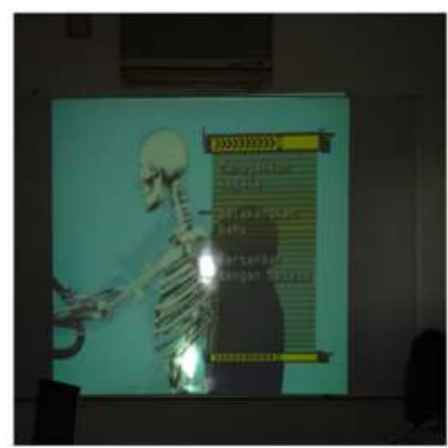

(D)

Fig. 2. Sample of (A) Poster (B) Demonstration (C) Pamphlet and (D) Video program 


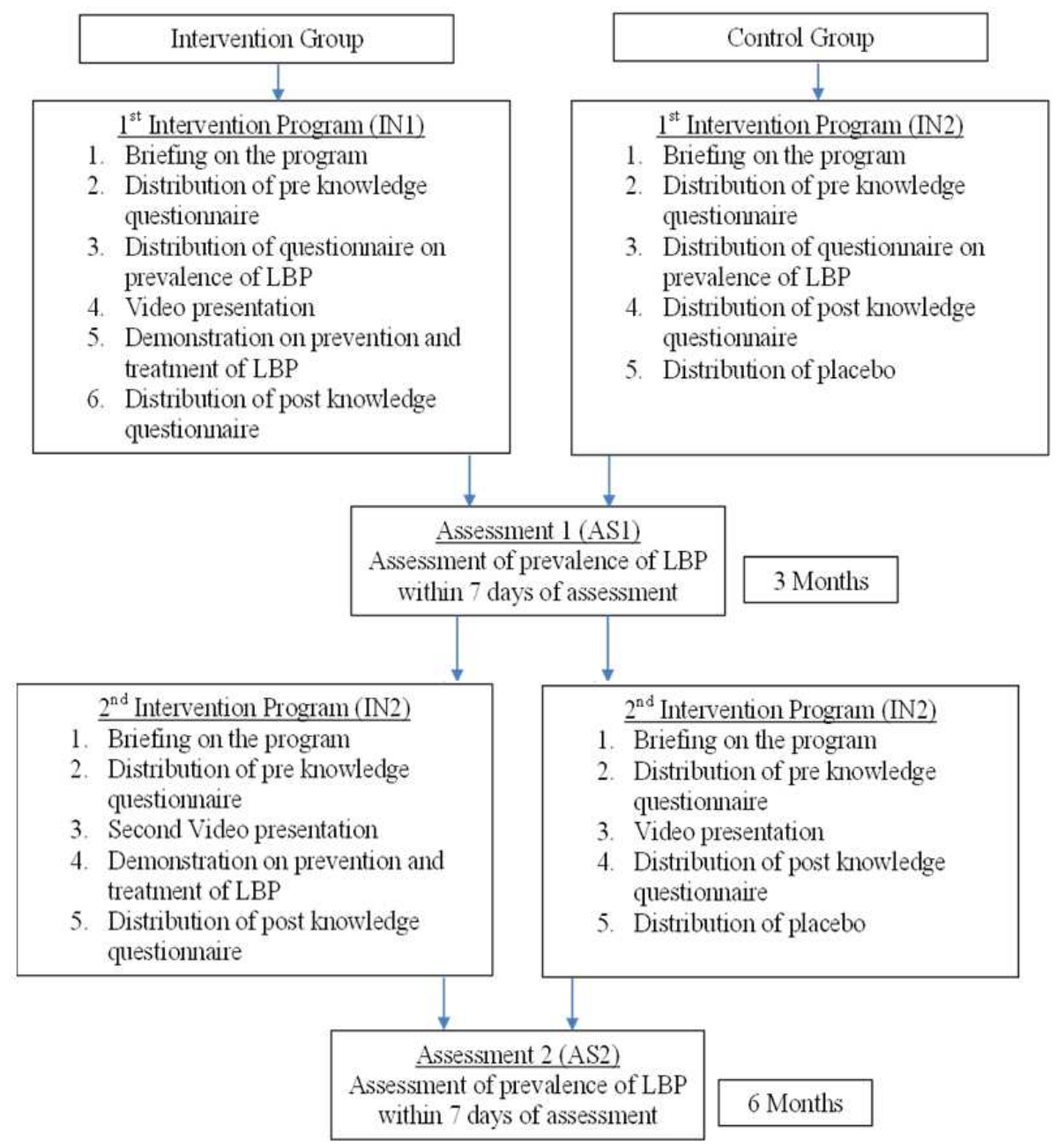

Fig. 3. Summary of the intervention program in reducing LBP among malaysian commercial vehicle drivers

Nevertheless, the mortality factor was not being completely controlled, however the sample size was considered adequate in reducing the effects of experimental mortality. On the other hand, randomization of group selection was also used to control differential selection effects and selection maturation interaction effects. The contamination effect was controlled by appointing instructors and demonstrator in performing the intervention program rather than the researcher performing the intervention program on his own. Therefore the increase in knowledge was solely due to implementation and introduction of intervention programs.

\subsection{Statistical Analysis}

In this study, the Statistical Package for Social Science (SPSS) version 13 was used in univariate and bivariate analysis (SPSS, 2005). Univariate analysis was used to describe descriptive statistics such as frequencies, means and standard deviations of sociodemographies, working characteristics and knowledge scores of pre-IN1 and post-IN1, pre-IN2 and post-IN2. The independent t-test was used to compare the mean score difference of knowledge in pre and post-IN1, pre and post-IN2 for both groups.

The three prevalence of LBP during the past 7 days (before-intervention, AS1 and AS2) were compared in each study group. Consequently, the patterns of prevalence (pre-intervention, AS1 and AS 2) of the two study groups (intervention versus control) were compared. All were done by using cross-sectional time-series random-effects logit models. 

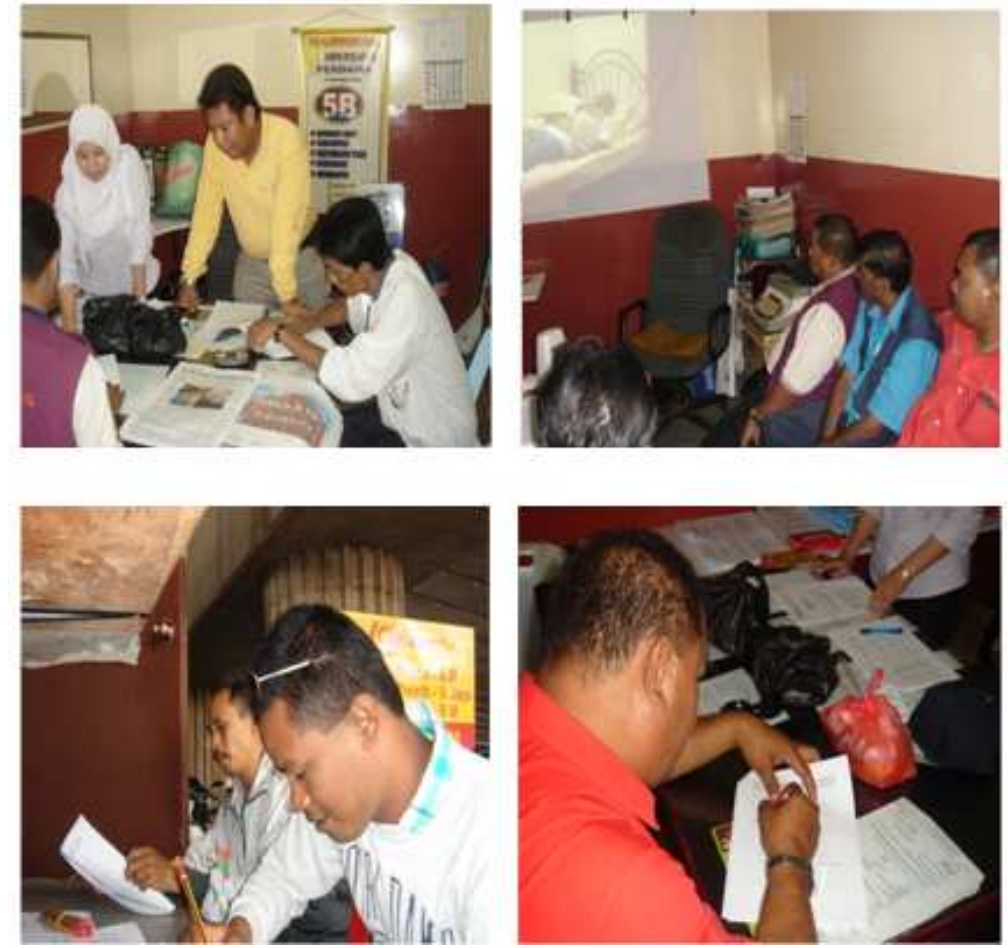

Fig. 4. Picture of video and questionnaire session in one of the bus company

The cross sectional time-series random-effect logit model was used as it was able to analyze categorical data from the complained of LBP among the drivers. In addition, the analysis will enable us to determine the overall pattern of both control and intervention group between baseline and post-IN1, baseline and post-IN2 and the overall pattern or effect due to time.

The random-effects model tests the individual (clusterspecific) effect rather than the group effect (Hosmer and Lemeshow, 2000). Intercooled Stata 7.0 for Windows was used for the analysis (StataCorp, 2001). The series variable was coded as ' 0 ' for before intervention, ' 1 ' for AS 1 and ' 2 ' for AS2. The series variable and the group variable (' 0 ' for control and ' 1 ' for intervention group) were the main independent variable.

To compare the time-effect (series variable) between the two study groups, the interaction term (between the series and group variables) was created and tested for its significant level in the model. The data were presented with odds ratios, their 95\% Confidence Intervals (CI), test statistics and $\mathrm{P}$ values. For multiple tests, $\mathrm{P}$ values are multiplied with number of tests (Bonferroni procedure) and therefore, $p<0.05$ is considered statistically significant for all hypotheses tests in this study.

\subsection{Ethical Clearence}

This study was approved by the Research and Ethics Committee of the Faculty of Medicine and Health Sciences, Universiti Putra Malaysia (reference: UPM/FPSK/100-11/40Jld.3).

\section{RESULTS}

\subsection{Socio-Demography and Working Characteristic}

The results from Table 1 show that most of the respondents are in their early 40's with monthly income of RM 987 (USD = 395). Respondents were mainly of Malay ethnicity, which is the dominant race in Malaysia and were educated up to lower secondary school. Working characteristics show that most had been driving for nearly 10 years with an average duration of $10 \mathrm{~h}$ daily and completed an average of 5 trips a day with each trip lasting for about $2.10 \mathrm{~h}$. An average of $20 \mathrm{~min}$ of resting was given between each trip. Most did not engage in part time work and only work permanently as bus drivers. Seventy-eight percent had previous working 
experience, $47 \%$ of which was related to driving. Seventy-nine percent worked were on weekly shifts. More than $60 \%$ complained of exposure to whole body vibration, while majority claimed that their seats and steering wheels are adjustable.

\subsection{Knowledge on Intervention Program}

Table 2 shows the knowledge regarding LBP from pre-IN1 to post-IN2. The results showed an increase of knowledge of the risks of LBP from 34.0 to $36.6 \%$ after post IN1 and an increase from $38.3 \%$ in pre-IN2 to $57.4 \%$ after post-IN2. Non-invasive treatment of LBP also showed an increase in trend from $46.7 \%$ (preIN1) to $71.6 \%$ in post-IN1 and knowledge retained in pre-IN2 (75\%) and increase up to $86 \%$ (post-IN2).

Correct seating methods were high at pre-IN1 and increased up to $84 \%$ in post-IN1 with a slight increase in the correct seating methods in pre-IN2 $(86 \%)$ and $88 \%$ in post-IN2. In the exercise program, the trend was found to be slightly different, morning exercise (after waking up in the morning) was found to increase from
$51.8 \%$ (pre-IN1) to $75 \%$ in post-IN1 and maintained at $78 \%$ during pre-IN2 and increased after post-IN2 (83\%). Exercise before driving was $34.0 \%$ at pre-IN1, increased after post-IN1 but reduced slightly during pre-IN2 (63\%) and slight increment after post-IN2 (71.9\%). Exercise while seating in the bus and exercise during resting period also had a similar trend as shown in Table 2.

In calculating the knowledge score received by the respondents, the results (Table 3) showed that pre-IN1, no significant difference was observed between the control and intervention group $(p=0.288)$. However, a significant increase of knowledge was observed among the intervention group after post-IN1 $(\mathrm{p}<0.0001)$ compared to the control group. Pre-IN2 showed that the mean score for control group remained the same, although there was a slight reduction of score level among the intervention group, the score was found to be significantly higher among those in intervention group $(\mathrm{p}<0.0001)$. Post-IN2 showed that the intervention group had significantly higher score compared to those in the control group $(\mathrm{p}<0.0001)$.

Table 1. Characteristics of sample population $(\mathrm{N}=197)$

\begin{tabular}{llll}
\hline Activity & $\mathrm{N}(\%)$ & Control & Experiment \\
\hline Regions & & & $23(24.5)$ \\
North & $42(21.3)$ & $19(18.4)$ & $59(62.8)$ \\
Central & $125(63.5)$ & $66(64.1)$ & $12(12.8)$ \\
Southern & $30(15.2)$ & $18(17.5)$ & $43.46(7.67)$ \\
Age & $43.51(7.29)$ & $43.6(6.97)$ & RM 1001.87 (376.97) \\
Monthly income & RM 987.25(382.70) & RM 973.92(389.2) & $79(84.0)$ \\
Ethnics & & & $2(2.1)$ \\
Malay & $160(81.2)$ & $81(78.6)$ & $12(12.8)$ \\
Chinese & $5(2.5)$ & $3(2.9)$ & $1(1.1)$ \\
Indians & $30(15.2)$ & $18(17.5)$ & $91(3.2)$ \\
Others & $2(1.0)$ & $1(1.0)$ & $3(3.2)$ \\
Marital status & & & 0 \\
Married & $186(94.9)$ & $96(93.2)$ & $01(1.1)$ \\
Bachelor & $9(4.6)$ & $6(5.8)$ & $33(35.1)$ \\
Divorcee & $(0.5)$ & $1(1.0)$ & $31(33.0)$ \\
Education level & & & $25(26.6)$ \\
No formal education & $1(0.5)$ & $26(25.2)$ & $4(4.3)$ \\
Primary school & $59(30.1)$ & $43(41.7)$ & $106.8(95.5)$ \\
Lower secondary school & $73(37.2)$ & $31(30.1)$ & $10.24(2.70)$ \\
Upper secondary school & $62(31.7)$ & $1(1.0)$ & $59.4(18.1)$ \\
Tertiary education & $1(0.5)$ & $118.55(98.55)$ & $114.7(48.2)$ \\
Working history & $112.87(97.02)$ & $10.77(7.48)$ & $4.96(2.19)$ \\
Working experience (Months) & $10.52(5.71)$ & $60.27(17.68)$ & $17.5(9.81)$ \\
Average hours driving daily & $59.85(17.81)$ & $135.86(144.06)$ & $5.18(2.61)$ \\
Average hours driving weekly & $125.67(109.21)$ & $22.63(24.46)$ & \\
Average time per trip (min) & $5.07(2.42)$ & & \\
Total trip daily & $20.15(18.97)$ & & \\
Resting after a trip (min) & & &
\end{tabular}


Table 2. Level of Knowledge of LBP between groups within intervention programs

\begin{tabular}{lllll}
\hline & Pre IN1 & Post IN1 & Pre IN2 & Post IN2 \\
\hline Sources of LBP & & & & \\
Ergonomics Factors & $67(34.0)$ & $72(36.55)$ & $62(38.30)$ & $93(57.40)$ \\
$\begin{array}{l}\text { Other factors } \\
\text { No answers }\end{array}$ & $94(47.70)$ & $103(52.30)$ & $86(53.10)$ & $65(40.10)$ \\
LBP treatment without & $36(18.30)$ & $22(11.20)$ & $14(8.00)$ & $4(2.50)$ \\
$\begin{array}{l}\text { consultation from physician } \\
\text { Correct seating position }\end{array}$ & $92(46.70)$ & $141(71.60)$ & $121(75)$ & $139(85.8)$ \\
when in a bus & $128(65)$ & $165(83.8)$ & $137(85.60)$ & $142(87.65)$ \\
Morning exercise & & & & \\
Exercise before driving & $102(51.80)$ & $148(75.10)$ & $126(77.78)$ & $134(83.10)$ \\
Exercise while seating in bus & $67(34.00)$ & $130(66.00)$ & $102(63.00)$ & $115(71.90)$ \\
Exercise while resting & $76(38.60)$ & $133(67.50)$ & $103(63.60)$ & $121(75.90)$ \\
\hline
\end{tabular}

Table 3. Mean differences of knowledge scores between groups

\begin{tabular}{|c|c|c|c|c|c|c|}
\hline & \multicolumn{6}{|l|}{ Group } \\
\hline & $\begin{array}{l}\text { Control } \\
(\text { Mean } \pm \text { Sd })\end{array}$ & $\begin{array}{l}\text { Intervention } \\
(\text { Mean } \pm \text { Sd })\end{array}$ & $F$ value & $\mathrm{T}$ value & $\mathrm{P}$ value & $95 \% \mathrm{CI}$ \\
\hline Pre-IN1 & $3.34(2.25)$ & $2.99(2.23)$ & 0.017 & 1.064 & 0.288 & $(-0.29,0.97)$ \\
\hline Post-IN1 & $3.63(2.14)$ & $9.46(3.31)$ & 7.467 & -14.509 & $0.000 * * *$ & $(-6.62,-5.03)$ \\
\hline Pre-IN2 & $3.92(1.96)$ & $7.50(3.64)$ & 16.40 & -7.689 & $0.000 * * *$ & $(-4.46,-2.63)$ \\
\hline Post-IN2 & $4.01(2.01)$ & 11.88 (3.77) & 18.30 & -16.547 & $0.000 * * *$ & $(-8.82,-6.93)$ \\
\hline
\end{tabular}

*** Significant at $\mathrm{p}<0.001$

Table 4. The patterns (baseline -> AS1 -> AS2) of LBP prevalence in groups

\begin{tabular}{|c|c|c|c|c|c|c|c|}
\hline Control & $\mathrm{n}(\%)$ & OR & $(95 \% \mathrm{CI})$ & Z Stat. & $\mathrm{P}$ value & $\begin{array}{l}\chi^{2}(\mathrm{df}) \\
{[\mathrm{P} \text { value }]}\end{array}$ & $\begin{array}{l}\chi^{2}(\mathrm{df}) \\
{[\mathrm{P} \text { value }]}\end{array}$ \\
\hline Baseline & $30(29.4)$ & & & & & & \\
\hline Post-IN1 & $24(27.0)$ & 0.79 & $(0.37,1.73)$ & -0.58 & $0.561^{\mathrm{a}}$ & $1.14(2)$ & \\
\hline Post-IN2 & $25(32.9)$ & 1.25 & $(0.56,2.76)$ & 0.54 & $0.588^{\mathrm{b}}$ & {$[0.564]^{\mathrm{c}}$} & \\
\hline Intervention & & & & & & & $8.41(2)$ \\
\hline Baseline & $36(38.3)$ & & & & & & {$[0.015]^{\mathrm{d}}$} \\
\hline Post-IN1 & $21(23.6)$ & 0.40 & $(0.19,0.86)$ & -2.35 & $0.019^{\mathrm{a}}$ & $11.34(2)$ & \\
\hline Post-IN2 & $14(17.7)$ & 0.25 & $(0.10,0.58)$ & -3.19 & $0.001^{\mathrm{b}}$ & {$[0.003]^{\mathrm{c}}$} & \\
\hline
\end{tabular}

${ }^{\mathrm{a}}$ Post1 Vs baseline ${ }^{\mathrm{b}}$ Post2 Vs baseline ${ }^{\mathrm{c}}$ Overall pattern or time effect ${ }^{\mathrm{d}}$ Comparison of the overall patterns between control and intervention groups

$\mathrm{OR}=$ Odds Ratio; $\mathrm{CI}=$ Confidence Interval; Stat. $=$ Statistic $; \mathrm{df}=$ degrees of freedom

Table 5. Post-hoc comparison of the pattern of LBP prevalence (baseline to AS1 and baseline to AS2) between groups

\begin{tabular}{llll}
\hline Pattern & $\mathrm{Z}$ stat & $\mathrm{P}$ value & $\mathrm{P}$ value $^{\mathrm{a}}$ \\
\hline Baseline to Post 1 & -1.33 & 0.182 & 0.546 \\
Post 1 to Post 2 & -1.44 & 0.151 & 0.453 \\
Baseline to Post 2 & -2.72 & 0.006 & 0.018 \\
\hline
\end{tabular}

${ }^{\mathrm{a}} \mathrm{P}$ values are corrected with Bonferroni procedure for multiple tests

\subsection{Intervention Program in Reducing LBP}

The prevalence of LBP on three occasions (as the pattern of prevalence) for both intervention and control groups were presented in Table 4 and Fig. 5. It shows that the prevalence of LBP significantly reduced in post-
IN1 $(p=0.019)$ (A reduction from 36 cases to only 21 cases after 3 month of intervention) and further significantly reduced in post-IN2 $(\mathrm{p}=0.001)$ (with a total of 22 cases) compared to the baseline in the intervention group. After the IN1, the odds of getting back pain was $40 \%$ of the odds of the baseline $(\mathrm{OR}=$ $0.40)$ whereas it became $25 \%$ after the IN2 $(\mathrm{OR}=0.25)$.

However, in control group, the pattern was slight reduction in post-IN1 (a reduction of 5 cases) and an increase of 1 cases in post-IN2, with no statistically significant difference $(\mathrm{p}=0.561$ and $\mathrm{p}=0.588$ respectively) (Table 4). The overall prevalent pattern comparison between the two groups was statistically significant $(\mathrm{p}=0.015)$. 


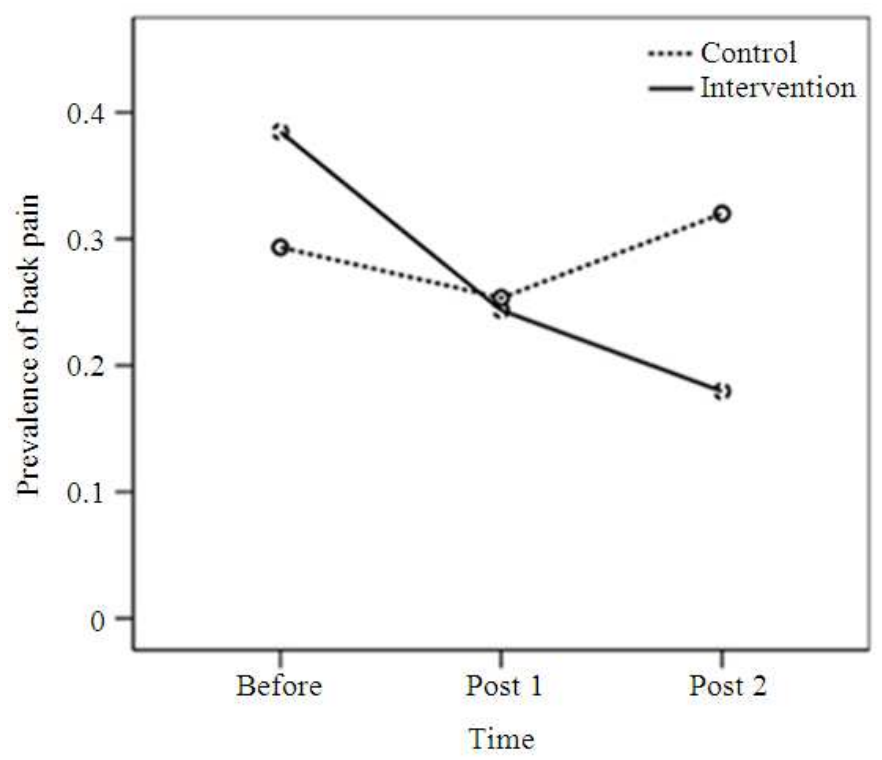

Fig. 5. The patterns of LBP prevalence (baseline $\rightarrow$ AS1 $\rightarrow$ AS2) in both groups

Further post-hoc analysis, presented in Table 5 revealed that the comparison of the pattern involving baseline to post-IN1 between the intervention and control groups did not show significant difference $(\mathrm{p}=$ 0.546). Similarly, the second part of pattern involving post-IN1 to post-IN2 was also not significantly difference between the two study group $(\mathrm{p}=0.453)$. However, the baseline to post-IN2 pattern was significantly different between two study groups $(\mathrm{p}=$ 0.018). Overall, the analysis revealed that the intervention group has significant reduction of LBP prevalence after giving two interventions as compared to the control group.

\section{DISCUSSION}

\subsection{Knowledge Level}

Demographic information of LBP database, age, income and part time work done by the respondents were randomly selected to ensure that no significant difference was observed when IN1 was introduced in the study.

The study only represented 2 major ethic groups mainly Malay and Indian since the Chinese were not keen on working as bus drivers given that working as bus drivers is considered as a low income job. Most of Malaysian bus drivers had lower secondary education and therefore had difficulties in answering questions regarding LBP. This is because the questions given needed them to memorize issues and factors regarding LBP management. Therefore any tool to be used for interview and training package must be simple and easily understood by the drivers.

The study showed that pre-IN1 showed no significant difference between the two groups indicating that neither groups had ever been exposed to any previous programs enhancing the knowledge on managing LBP, risk factors, treatment of LBP and exercise in strengthening their back muscles. After the introduction of IN1, the knowledge of LBP management was found to increase significantly compared to the control group although it was still lower than the expected score. This can be related to the age and the level of education of the driver. The average age was 44 years old, which suggests there might be difficulties of memorizing and understanding the details of the intervention program.

The level of education also supports the result showing that majority of the drivers was educated up to lower secondary school and may have difficulties in understanding the contents of the program. This is because the content developed include technical and scientific information that need more simple explanation to the drivers. However, the pattern of knowledge score was maintained for the intervention group after pre-IN2 and increased significantly after post-IN2. This indicates that the re-introduction of intervention package after six months successfully maintained the level of knowledge 
among the intervention group. In order to maintain easy understanding and use by the intervention group, the properties of the intervention package, which incorporated a video $\mathrm{CD}$ presentation using a simple and easy narration in local Malay language, animation in showing risks of LBP, simplified short duration exercise without any rigorous training and non-clinical treatment of hot and cold packs that were easy to practice. Pamphlet showed illustrations that were easy to remember, practice and simple instructions to the drivers. The poster was designed for them for easy view on the source of LBP. As the preference, the video presentation was the most preferred intervention program followed by the demonstration by our demonstrators and pamphlet. The poster given was the least preferred by them. The demonstrator managed to motivate and remind the participants in practicing the exercise program, reading the pamphlet and poster during both IN1 and IN2. Therefore for a period of 6 months, the intervention program managed to have a modest impact of LBP improvement among the participants.

\subsection{Intervention LBP}

The prevalence of LBP showed that the prevalence during baseline (1st phase) showed no significant difference between two groups; three months after introduction of IN1 also showed no significant reduction of LBP prevalence between both groups. However, a significant reductions in the number of LBP complaints was observed after 6 months of intervention. The finding shows that an intervention program to reduce LBP for bus drivers must take into consideration of the average age, level of education, working characteristics, such as daily working hours and resting period of the driver; and develop a program that contains re-introduction of the program and not time consuming. The effect of exercising before, during and after driving can only be seen after six months of practice as suggested by Westgaard and Winkel (1997) using the hypothetical model of intervention impact as function of exposure and time. We can assume that any changes in the prevalence of LBP after an intervention program was introduced might not take an immediate effect rather a latency period for it to have an effective outcome as suggested (Buckle, 1997; Zwerling et al., 1997).

Although we did not observe a significant reduction after IN1, the reduction in IN2 indicated that the intervention package developed was suitable to be used by bus drivers. The intervention program was successful because of the characteristics of the bus drivers working conditions, age and level of education; the exercise package, non-medical treatment and lifting technique developed, took less than $5 \mathrm{~min}$ for each of it to be implemented, therefore the total time taken by the driver can be considered as non-time consuming. This is important as the drivers working routine and schedule indicated that they will start working around 5 am in the morning and must check the condition of the buses daily to avoid any major engine problems. In addition, they were required to do housekeeping of the bus. Therefore, any exercise program developed for bus drivers must not consume much time early in the morning. The exercise program while in the driving seat is easy to perform and implement since they are able to exercise frequently without having to move from the seat.

Physiologically, physical exercise has been shown to be effective to increase the Range Of Motion (ROM) and hence potentially prevent MSD (Costa and Vieira, 2008; Sanudo et al., 2011). The exercise can be done regularly among the bus drivers and can be extended to private car drivers especially when waiting at the traffic lights or during heavy traffic congestion. The exercise during resting can also be seen to be effective since they were given an ample resting period (average of $20 \mathrm{~min}$ ) per trip. Although there was evidence that an effective exercise program should be done approximately up to $130 \mathrm{~min}$ (low intensity exercise; with warming up (10 $\mathrm{min})$, strength training ( $1 \mathrm{~h}$ and $15 \mathrm{~min}$ ) and cooling down $(5 \mathrm{~min})$ ) for it to show a strong evidence of effectiveness with the current working conditions, it is difficult and unlikely suitable for bus drivers to expend their time for the exercise (Heymans et al., 2004). In addition, the evidence shows that the effectiveness of short duration program is more effective compared to a program that is time consuming (Mikhail et al., 2005). There is also evidence that effectiveness of intervention program cannot be distinguished between low and high intensity programs (Tulder et al., 2003).

A short exercise program may motivate the drivers to practice and implement the program frequently. The evidence showed that exercise compliance may decrease rapidly overtime and the need for compliance of a simple and short duration program is important (Becker, 1985; Krause, 1966; Oldridge, 1982). Although we did not emphasize the motivational score, studies have had found that motivation do play an important role in sustaining regular exercise (Friedrich et al., 1998). It can easily be hypothesized that a program that is time consuming cannot have a greater effect since it was not continuously done, as evidence has shown that most intervention programs would not have a long-term 
impact compared to a shorter exercise program, which is easy, low intensity and can be implemented continuously (Lotters and Burdof, 2002). In addition, a self-care program for reduction and prevention of LBP should be customized to not only a patient's individual needs and routines but extended based on their daily working routine (Bartlett, 1982; Dishman, 1982).

Introduction and re-introduction of intervention programs worked very well with bus drivers since most of them had lower education level and with older age, an intervention program that only introduce once might have a low impact on the awareness and the urge to perform the exercises. Therefore the introduction of the first intervention program most likely was useful in strengthening their knowledge, practical ability and motivation. The second intervention program was useful to remind them to practice the exercise and intervention program provided.

\subsection{Study Limitation}

Although we are able to observe a significant reduction, there are limitations to this study and future research should emphasize the effects of each intervention package, namely exercise program, demonstration, pamphlet or poster. We are unable to determine this since the difficulty to recruit a larger sample for each group. Although the sample size is relatively large for baseline data, the intervention sample group was small for a more meaningful multivariate analyses in particular time series evaluation. Motivation outcome must be measured to determine the long term impact of the intervention program. The use of other LBP outcome scores such as low back outcome scale questionnaire, pain intensity and Waddell's physical impairment, should be encouraged although it is not suitable for our study (Carlsson, 1983; Greenough and Fraser, 1992; Waddell, 1991). The main reason is that both groups include participants with and without LBP and the outcome may be misleading.

Although the use of long term health promotion has the capacity to reduce the prevalence of LBP, the effect in reducing LBP is much lower compared to engineering intervention program. From our unpublished data, the cost effective analysis between the two type of ergonomics intervention method indicate that the use of ergonomics seat is significantly effective in reducing muscle fatigue (18.33 $\mu \mathrm{v})$ compared to exercise $(0.54 \mu \mathrm{v})$. In addition, the reducing muscle fatigue is significantly lower when using ergonomic seat (6.6 USD) compared to 37.9 USD when applying a series of exercise (Tamrin, 2008). Although the burden of work improvement fall on responsibility of the drivers, it should be consider a precursor for ergonomics improvement.

\section{CONCLUSION}

The study shows the intervention package developed and introduced to bus drivers was moderately succeeded in reducing the prevalence of LBP. Any future intervention program must be implemented at least twice to determine the overall effect rather than only introduce it once and observing the effect. A longer period of time (i.e., more than one year as intervention program developed by Johanning et al. (1996) may have a more significant result compared to a short intervention program. The knowledge in LBP management was found to be adequate and had instant impact in promoting intervention program; however there is a need of repetition of class intervention so as to maintain the level of knowledge among the intervention group.

An intervention program for bus drivers should be a holistic program that consists of health promotion program in video, pamphlet, poster and demonstration. The intervention program develop is a simple package that can be used not only in public buses, but can be generalize to other commercial vehicle drivers such as train and mass transit drivers and own private vehicle user due to the similarity of hazard exposure that include seat type, whole body vibration and awkward posture.

It is recommended that study in the future among bus drivers takes into the consideration the factors and limitation as addressed and discussed in this study for a meaningful outcome. The extent of the effect should also be tested individually of each intervention package and in combination of risk reduction through engineering control. Furthermore, research in the future should also holistically includes psychosocial and organizational factors and be allowed for longer period of intervention in a much robust study design which incorporates elements in this study.

\section{ACKNOWLEDGEMENT}

The study was supported by Ministry of Science and Innovation of Malaysia under the Intensified Research of Priority Area (IRPA) grant of 8th Malaysian Plan (0602-05-0000-PR0061/0). The researchers would like to thank all bus companies' administrators, participants and 
Malaysian National Occupational Risk Management System Program (NORMS) group.

\section{REFERENCES}

Aaras, A., 1994. The impact of ergonomic intervention on individual health and corporate prosperity in a telecommunications environment. Ergonomics, 37: 1679-1696. DOI: 10.1080/00140139408964945

Amick, B.C., M.M. Robertson, K. DeRango, L. Bazzani and A. Moore et al., 2003. Effect of office ergonomics intervention on reducing musculoskeletal symptoms. Spine, 28: 2706-2711. PMID: 14673374

Anderson, R., 1992. The back pain of bus drivers. Prevalence in an urban area of California. Spine, 17: 1481-1488. PMID: 1471006

Bartlett, E.E., 1982. Behavioral diagnosis: A practical approach to patient education. Patient Couns Health Educ., 4: 29-35. DOI: 10.1016/S07383991(82)80032-3

Becker, M.H., 1985. Patient adherence to prescribed therapies. Med. Care, 23: 539-555. PMID: 4010350

Bovenzi, M. and C.T.J. Hulshof, 1999. An updated review of epidemiologic studies on the relationship between exposure to whole-body vibration and low back pain. Int. Archvies Occupat. Environ. Health, 72: 351-365. DOI: 10.1007/s004200050387

Brisson, C., Montreuil, S. and L. Punnet, 1999. Effect of an ergonomics training program on workers with video display units. Scand J. Work Environ. Health, 25: 255-263. DOI: 10.5271/sjweh.432

Buckle, P., 1997. Musculoskeletal injuries and their prevention-assessment of interventions. Proceedings of the 13th Congress of the International Ergonomics Association Tampere Finland, (TF' 97), pp: 141-143.

Cambron, J.A., M.R. Gudavalli and D. Hedeker, 2006. One year follow-up of a randomized clinical trial comparing flexion distraction with an exercise program for chronic low back pain. J. Alternative Complementray Med., 12: 659-668. DOI: 10.1089/acm.2006.12.659

Carlsson, A.M., 1983. Assessment of chronic pain. I. aspect of the reliability and validity of the visual analogue scale. Pain, 16: 87-101. DOI: 10.1016/0304-3959(83)90088-X

Costa, B.R. and E.R. Vieira, 2008. Stretching to reduce work-related musculoskeletal disorders: A systematic review. J. Rehabilitat. Med., 40: 321-328. DOI: $10.2340 / 16501977-0204$
Dishman, R.K., 1982. Compliance/adherence in healthrelated exercise. Health Psychol., 1: 237-267. DOI: 10.1037/0278-6133.1.3.237

Evanoff, B.A., P.C. Bohr and L.D. Wolf, 1999. Effect of a participatory ergonomics team among hospital orderlies. Am. J. Ind. Med., 35: 358-365.

Forsell, M.Z., 1980. The swedish back school. Physiotherapy, 66: 112-114.

Forsell, M.Z., 1981. The back school. Spine, 6: 104-106. DOI: 10.1097/00007632-198101000-00022

Fredriksson, K., C. Bildt, G. Haag and A. Kilbom, 2001. The impact on muscduloskeletal disorders of changing physical and psychological work environment conditions in the automobile industry. Int. J. Ind. Ergonom., 28: 31-45. DOI: 10.1016/S0169-8141(01)00011-7

Friedrich, M., G. Gittler, Y. Halberstadt, T. Cermak and I. Heiller, 1998. Combined exercise and motivation program: Effect on the compliance and level of disability of patients with chronic low back pain: A randomized controlled trial. Archives Phys. Med. Rehabilitat., 79: 475-487. PMID: 9596385

Greenough, C.G. and R.D. Fraser, 1992. Assessment of outcome in patients with low back pain. Spine, 17: 36-41. PMID: 1531553

Guo, H.R., Y.C. Chang, W.Y. Yeh, C.W. Chen and Y.L. Guo, 2004. Prevalence of musculoskeletal disorder among workers in taiwan: A nationwide study. J. Occupatinal Health, 46: 26-36. DOI: 10.1539/joh.46.26

Heymans, M.W., H.C.W.D. Vet, P. Bongers, B.W. Koes and W.V. Mechelen, 2004. Back school in occupational health care: Design of a randomized controlled trial and cost effectiveness study. J. Man Physiol. Therap., 27: 457-465. DOI: 10.1016/j.jmpt.2004.06.004

Hosmer, D.W. and S. Lemeshow, 2000. Applied logistic regression. 2nd Edn., John Wiley and Sons Inc., New York, NY., ISBN-10: 9780471356325

Johanning, E., 1991. Back disorders and health problems among subway train operators exposed to wholebody vibration. Scand J. Work Environ. Health, 17: 414-419. DOI: $10.5271 /$ sjweh. 1681

Johanning, E., P. Landsbergis, H. Geissler and R. Karazmann, 1996. Cardiovascular risk and back disorder intervention study of mass transit operators. Int. J. Occupatinal Environ. Health, 2: 79-87. DOI: 10.1179/oeh.1996.2.2.79 
Johansson, J.A., R. Kadefors and S. Rubenowitz, 1993. Musculoskeletal symptoms, ergonomic aspects and psychological factors in two different truck assembly concepts. Int. J. Ind. Ergonom., 12: 35-48. DOI: 10.1016/0169-8141(93)90036-D

Koda, S. and H. Ohara, 1999. Preventive effects on low back pain and occupational injuries by providing the participatory occupational safety and health program. J. Occupational Health, 41: 160-165. DOI: 10.1539/joh.41.160

Krause, M.S., 1966. A cognitive theory of motivation for treatment. J. General Psychol., 75: 9-19. DOI: 10.1080/00221309.1966.9710345

Kuorinka, I., B. Jonsson A. Killbom, H. Vinterberg, F.B. Sorensen and G. Andersson et al., 1987. Standardised nordic questionnaires for the analysis of musculoskeletal symptoms. Applied Ergonom., 18: 233-237. DOI: 10.1016/0003-6870(87)90010-X

Lewis, R.J., M. Fogleman, J. Deeb, E. Crandall and D. Agopsowicz, 2001. Effectiveness of a VDT ergonomics training program. Int. J. Ind. Ergonom., 27: 119-131. DOI: 10.1016/S0169-8141(00)00043-3

Lotters, F. and A. Burdof, 2002. Are changes in mechanical exposure and musculoskeletal health good performance indicators for primary interventions? Int. Archives Occupational Environ. Health, 75: 549-561. DOI: 10.1007/s00420-002-0368-7

Magnusson, M.L., M.H. Pope, D.G., Wilder and B. Areskoug, 1996. Are occupational drivers at an increased risk for developing musculoskeletal disorders? Spine, 21: 710-717. PMID: 8882693

Mikhail, C., K.N. Bitensky, M. Rosignol and J.P. Dumas, 2005. Physical therapists' use of interventions with high evidence of effectiveness in the management of a hypothetical typical patient with acute low back pain. Phys. Ther., 85: 11511167. PMID: 16253045

MOT, 2010. Annual Report.

MOT, 2012. Annual Report.

Moore, J.S. and A. Garg, 1998. The effectiveness of participatory ergonomics in the red meat packing industry evaluation of a corporation. Int. J. Ind. Ergonom., 21: 47-58. DOI: 10.1016/S01698141(97)00024-3

OSHA., 1999. Occupational safety and health administration. Proposal for ergonomics program standard: Frequently asked questions.
Oldridge, N.B., 1982. Compliance and exercise in primary and secondary intervention prevention of coronary heart disease: A review. Preventive Med., 11: 56-70. DOI: 10.1016/0091-7435(82)90005-6

Poosanthanasarn, N., C. Lohachit, W. Fungladda, S. Sriboorapa and C. Pulkate, 2005. An ergonomics intervention program to prevent worker injuries in a metal autoparts factory. Southeast Asian J. Trop Med. Public. Health, 36: 512-522. PMID: 15916064

Pope, M.H., K.L. Goh and M.L. Magnusson, 2002. Spine ergonomics. Annual Revies Biomedcal Engineer., 4: 49-68.

DOI: 10.1146/annurev.bioeng.4.092101.122107

Poulsen, K.B., S.H. Jensen, E. Bach and J.F. Schostak, 2007. Using action research to improve health and the work environment for 3500 municipal bus drivers. Edu. Ac. Res., 15: 75-106. DOI: 10.1080/09650790601151228

Robertson, M.M., B.C. Amick, N. Hupert, M.P. Dionne and E. Cha et al., 2002. Effects of a participatory ergonomics intervention computer workshop for university students: A pilot intervention to prevent disability in tomorrow's workers. Work, 18: 305314. PMID: 12441571

Roland, M. and M. Dixon, 1989. Randomized controlled trial of an educational booklet for patients presenting with back pain in general practice. J. R. Coll. Gen. Pract., 39: 244-246. PMID: 2556518

Rosecrance, J.C. and T.M. Cook, 2000. The use of participatory action research and ergonomics in the prevention of work-related musculoskeletal disorders in the newspaper industry. Applied Occupational Environ. Hygiene, 15: 255-262. DOI; 10.1080/104732200301575

Sanudo, B., L. Carrasco, M.D. Hoyo and N. Ochiana, 2011. Are improvements in physical fitness after an exercise program related to the symptomatology in patients with fibromyalgia. J. Social Sci., 7: 375379. DOI: $10.3844 /$ jssp.2011.375.379

SPSS, 2005. Inc, 444 North Michigan Avenue, Chicago, IL.

StataCorp, 2001. Stata statistical software: Release 7.0. College Station, TX: Stata Corporation.

Tamrin, S.B.M., K. Yokoyama, N. Aziz and S. Maeda, 2012. Association of risk factors with musculoskeletal disorders among male commercial bus drivers in Malaysia. Human Factor Erognom. Service Industr. DOI: 10.1002/hfm.20387 
Tamrin, S.B.M., 2008. Cost effective analysis between health promotion and engineering intervention for Malaysian bus drivers. Mie University, Japan.

Tamrin, S.B.M., K. yokoyama, J. Jalaludin , N.A. Aziz and N. Jemoin et al., 2007. The association between risk factors and low back pain among commercial vehicle drivers in Peninsular Malaysia: A preliminary result. Indust. Health, 45: 268-278. DOI: 10.2486/indhealth.45.268

Tulder, V.M.W., A. Mahmivaara, R. Esmail, B.W. Koes, 2003. Exercise therapy for low back pain .Cochrane Database Syst Rev. PMID: 10796344

Waddell, G., 1991. Occupational low back pain, illness behavior and disability. Spine, 16: 683685. PMID: 1830698
Wahlstedt, K.G., C.H. Nygard, K. Kemmlert, M. Torgen, M.G. Bjorksten, 2000. The effect of a change in work organization upon the work environment and musculoskeletal symptoms among letter carriers. Int. J. Occupational Safety Ergonom., 6: 237-255. PMID: 10927669

Westgaard, R.H. and J. Winkel, 1997. Ergonomic Intervention research for improved musculoskeletal health: A critical review. Int. J. Industrial Ergonom., 20: 463-500. DOI: 10.1016/S0169-8141(96)00076-5

Zwerling, C., L.H. Daltroy, L.J. Fisne, J.J. Johnston and J. Melius et al., 1997. Design and conduct of occupational Injury intervention studies: A review of evaluation strategies. Am. J. Ind. Med., 32: 164179. PMID: 9215438 